\title{
Viscosity as a possible supplement to the empirical tests of bitumen
}

\author{
Michal Holý, ${ }^{1, *}$, and Eva Remišová ${ }^{1}$ \\ ${ }^{1}$ University of Žilina, Department of Civil Engineering, Slovak Republic
}

\begin{abstract}
The quality of bituminous binders used in the construction and maintenance of road surfaces is currently being assessed by empirical tests based on obtaining one value for specific boundary conditions that were designed around 100 years ago. However, these tests appear to be inadequate. Under laboratory conditions, all bitumen tests have the correct values, but if the bitumen binder is used in the asphalt mix in the road, sometimes we can see no standard properties and behavior than in the laboratory. We are increasingly faced with the issue of replacing empirical bitumen tests with performance related parameters as viscosity, complex shear modulus that can better and more accurately describe the behavior of bitumen not only in the laboratory but also in asphalt mixtures. In paper the viscosity results of ten bitumen samples (50/70 and $\mathrm{PmB} 45 / 80-75)$ at different temperatures are presented and compared with empirical tests as penetration and softening point.
\end{abstract}

\section{Introduction}

Asphalt mixtures are the most frequently used materials in the road pavement construction layers in the Slovak Republic. The total length of all communications in Europe exceeds 5 million kilometres, with asphalt roads accounting for more than $90 \%$ from this length. During 2014, more than 265 million tonnes of asphalt mixes were produced in Europe. Available figures [1] show that this is a significant part of the whole social cost and it is therefore essential to take care of the quality and durability of this building material. If the air voids and/or the different additives disappear, the asphalt mixture consists of two basic components - aggregate and bitumen binder, the weight of which most frequently ranges from $5 \%$ to $8 \%$. Despite the fact the aggregate is the largest part of the asphalt mixture, the properties of bitumen binder are also significant. Bitumen is a material of organic origin, which consists of a number of hydrocarbon compounds, which under a certain condition are subjected to a degradation process, due to the influence of heat, air oxygen and ultraviolet radiation, or their combinations, with which bitumen binders normally encounter in the production and laying of asphalt mixtures or during their service time.

Basic tests such as penetration and softening point were developed to assess and classify unmodified bitumen. The increased using of bitumen modification especially with polymers and other additives, the empirical approach is replaced by defining the performance-based

\footnotetext{
* Corresponding author: michal.holy@,fstav.uniza.sk
} 
requirements for binder properties [2] because "traditional" respectively "verified" tests such as softening point, penetration, and the breaking point appears at present to be insufficient for describe the behavior of bitumen binders. The current state of the asphalt roads has led to new ways and approaches for better describe the properties of binders and mixtures. One of this approach to assessment of bitumen in terms of operational performance is so-called "performance-based approach".

In the case of performance related characteristics the behavior is determined as a result of the repeated stress of the material in different forms of intervals (temperature, frequency, shear stress) are chosen, in which the bitumen binder is exposed to the observed effect. Use of modern equipments (DSR, RV, BBR) and functional procedures as well as requirements for bitumen binders in the temperature range to which the bitumen binder is exposed over the life cycle is shown on Figure 1.

While the DSR (Dynamic Shear Rheometer) [3] is a device that can describe the properties of bituminous binders in a wide range of temperatures and frequencies and is mostly used to describe properties at standard temperatures of pavements (susceptibility to permanent deformations or fatigue properties), rotational viscometers are more applicable to the description of properties at higher temperatures which are important for the processing of the bitumen binder but also for the laying and compaction of asphalt mixtures.

To define more precisely the behavior of bitumen and bituminous binders it is necessary to find new ways of assessing the properties. Bitumen binders behave as an elastic and viscous material, it is necessary to describe the temperature-dependent behavior. The viscosity of the bitumen binder could be the use as one of solutions. Dynamic viscosity of the bitumen binder is a part of qualitative parameters assessment of bituminous binders.

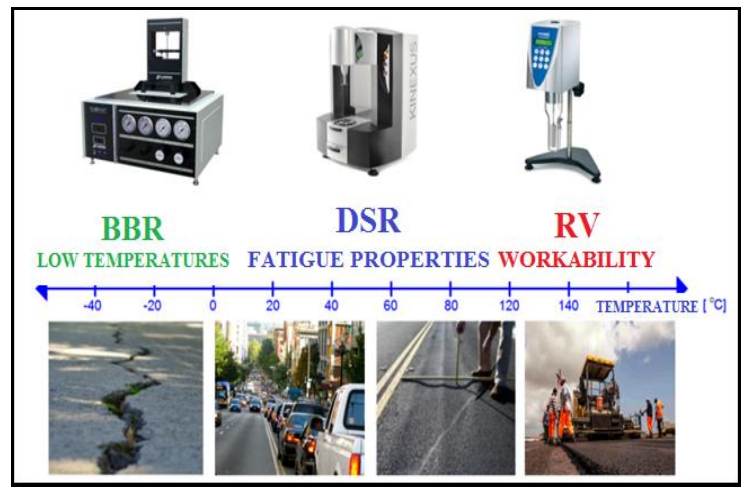

Fig. 1. Equipments and requirements for bituminous binders at different temperatures [1].

\section{Viscosity and performance-based approach}

Bitumen is a thermoplastic, viscoelastic material, which behavior depends on temperature, speed and size of the load. Viscoelastic character [4] means that by impact of external forces partially elastic deformation occurs (elastic component) and partially plastic strain occurs (viscous component). At low temperatures, respectively, at high frequencies of load (fast passing cars), the bitumen behaves as an elastic and solid material. The elastic part is deformed under load and after reducing the load, it is returned to the original shape. This behavior, however, lasts continues as long as exceeding the limits of bearing capacity and materials damage, it means the bitumen binders crack. At high temperatures, respectively, during long-term loading (parking vehicles), the bitumen behaves as a viscous material [5]. 
In theoretical investigation of the dependence of fluid motion a fictitious or-perfect fluid is often used. This term means incompressible liquid, which is not affected by temperature changes and it has a zero viscosity (it is completely liquid). Liquids in common practice are called - real fluids. They are compressible, have a certain non-zero viscosity and their volume dependents on the viscosity. In contrast with the ideal fluid, real fluids have an internal friction, which is created by the tangential forces between adjacent particles of fluid during movement.

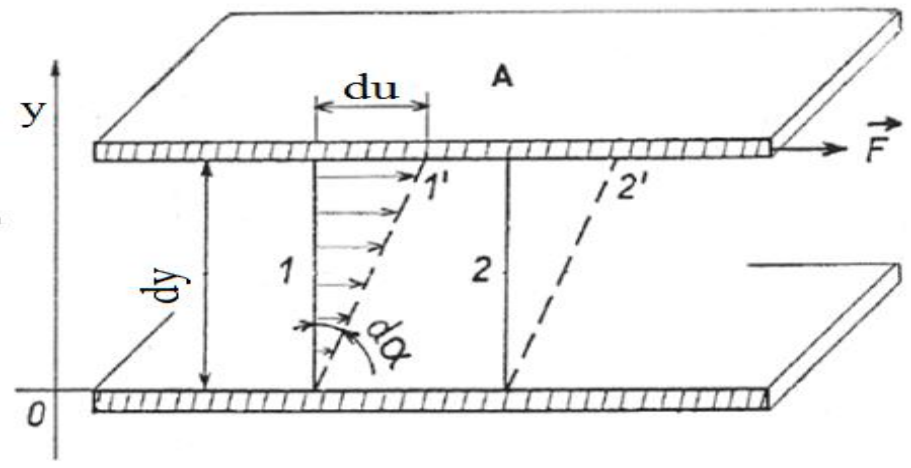

Fig. 2. Velocity distribution of flow in fluid - two plate model [6].

In the laminar flow, fluid movement occurs in layers on each other friction effect. Between the moving layers of fluid (Figure 2) there is a shear stress in direction $\mathrm{x}$ and the layers move at different speeds. Then, $d u / d x$ represents a gradient of velocity in a direction perpendicular to the movement of the fluid. And at the same time deformation $d x / d y$ layers occurs. It is defined by Newton's equations:

$$
\tau=\eta \cdot \dot{\gamma}
$$

where: $\tau$ - shear stress $[\mathrm{Pa}], \eta$ - dynamic viscosity [Pa.s], $\gamma$ - velocity gradient or shear rate $\left[\mathrm{s}^{-1}\right]$, which is given by $d u / d x$.

The viscosity of a fluid expresses its resistance to shearing flows. Its cause is the binding force through which the atoms, respectively, the molecules of the liquid consists. It is an important rheological property. Viscosity is a material property, depending on temperature and deformation rate. It is determined experimentally, using viscometers with a clearly defined flow geometry, and a velocity gradient value and a corresponding shear stress value can be determined [6]. A suitable viscometer is the Brookfield rotational viscometer for Couette flow.

\section{Tested materials and methodology}

Presented paper is focused on dependence between the viscosity and empirical tests as penetration and softening point. Within laboratory measurements there were studied the properties of binders for the production of asphalt mixes for asphalt pavement construction, paving grade bitumen 50/70 (A1 - A7) and polymer modified bitumen PMB 45/80-75 (MI$M 3)$. The following tests were performed:

-penetration at $25^{\circ} \mathrm{C}$ determined according EN 1426 [7]. Penetration is the expression of the binder stiffness under test conditions (temperature, load and time). 
-softening point determined according EN 1427 [8]. It is expression bitumen property at higher temperatures.

- dynamic viscosity at temperature 120, 130, 135, 140, 150, 160, 165, 170, 175, 180, 185 and $190^{\circ} \mathrm{C}$. Measurement of dynamic viscosity (ratio between the applied shear stress and the shear rate) in accordance with EN 13302 determines the viscosity using the instrument with the rotating spindle. This European Standard specifies a method for determination of the dynamic viscosity of modified and unmodified bituminous binders. The principle of dynamic viscosity measurement [9] is the torque applied to a spindle (e.g. a cylinder) rotating in a special container containing the test sample, measures the relative resistance of the spindle to rotation and provides a measurement of dynamic viscosity of the sample.
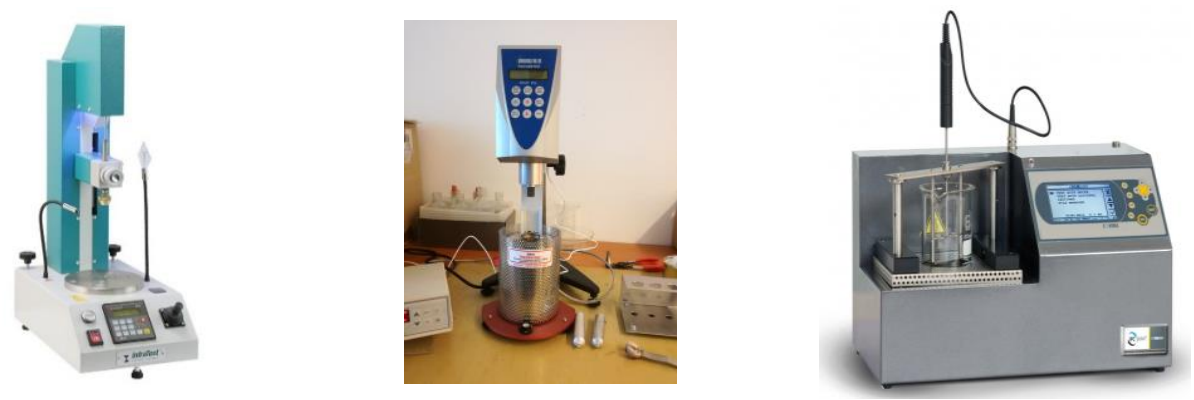

Fig. 3. Equipments for penetration (left) dynamic viscosity (middle) and softening point test of bitumen (right).

The experimental measurements of dynamic viscosity of selected bitumen were realized by Brookfield viscometer - model DV-II+PRO (Figure 3) with cylindrical spindle. To obtain representative results of bituminous binders the viscosity must always be measured at various test temperatures. Brookfield viscometer - model DV-II+PRO [4] allows direct measurement of the shear stress in $\mathrm{N.cm}^{2}$ and the viscosity in $\mathrm{mPa}$.s.

\section{Test results and discussion}

The values from measurements of softening point and penetration of tested bitumen binders are presented in Table 1. Despite the same grade of bitumen, we can observe a relatively high variability of results. In the case of paving grade bitumen, the range of softening points is from $48{ }^{\circ} \mathrm{C}$ to $51{ }^{\circ} \mathrm{C}$ and range of penetration is from 54.3 to $75.9 \times 0.1 \mathrm{~mm}$. In the case of polymer modified bitumen, the range of softening points is from $75.4{ }^{\circ} \mathrm{C}$ to $80.75{ }^{\circ} \mathrm{C}$ and range of penetration is from 54.6 to $74.3 \times 0.1 \mathrm{~mm}$. The results are within the prescribed limits (the only one exception is the A6 sample, which is out of range of penetration) for penetration (from 50 to $70 \times 0.1 \mathrm{~mm}$ for paving grade bitumen and from 45 to $80 \times 0.1 \mathrm{~mm}$ for modified bitumen) and softening point (from 46 to $54{ }^{\circ} \mathrm{C}$ for paving grade bitumen and $\geq 75{ }^{\circ} \mathrm{C}$ for paving grade bitumen) which are defined in the specifications for bitumen. Calculation to the penetration index, which expresses the temperature susceptibility of bitumen, we can see, that samples A3 and A4 are slightly different from others, because they have a lower PI value with compare to others values (however, all samples of bitumen belongs to the SOL-GEL group). For paving grade bitumen, the values are generally in range between -1 and +1 ; a higher PI indicates lower temperature susceptibility. 
Table 1. Results from the measurement of the bitumen binder empirical properties.

\begin{tabular}{|c|c|c|c|}
\hline SAMPLE & PENETRATION & SOFTENING POINT & $\begin{array}{c}\text { PENETRATION } \\
\text { INDEX }\end{array}$ \\
\hline A1 & $0.1 \mathrm{~mm}$ & ${ }^{\circ} \mathrm{C}$ & - \\
\hline A2 & 64.1 & 49.75 & -0.68 \\
\hline A3 & 63.8 & 49.75 & -0.69 \\
\hline A4 & 62.8 & 49 & -0.92 \\
\hline A5 & 61.0 & 48 & -1.26 \\
\hline A6 & 70.0 & 48.95 & -0.66 \\
\hline A7 & 54.3 & 48 & -0.70 \\
\hline M1 & 54.6 & 51 & -0.77 \\
\hline M2 & 74.3 & 80.75 & 4.67 \\
\hline M3 & 60.5 & 75.4 & 4.83 \\
\hline
\end{tabular}

The results of the dynamic viscosity measurement are shown in the Figure 4. From the results we can say that despite the same grading of bitumen, we can see the high variability of the results of dynamic viscosity (more visible for lower temperatures), with higher the temperature, the variability of values of dynamic viscosity is smaller for both bitumen. Different viscosity values for specific temperatures, despite the same grading of bitumen, we can be attributed to the fact that each of bitumen was from another manufacturer (both for paving grade bitumen and for modified bitumen - for modified bitumen show differences of dynamic viscosity of already 3 samples of bitumen). For all tested bitumen, the viscosity decreases with increasing temperature and also the modified bitumen have several times a higher values of dynamic viscosity with compared to paving grade bitumen. Shift in values of viscosity of tested modified bitumen is due to specific modifier, which was used in bitumen production. Paving grade bitumen have values of viscosity from temperature $160{ }^{\circ} \mathrm{C}$ almost on the same level, polymer modified bitumen is more significant.
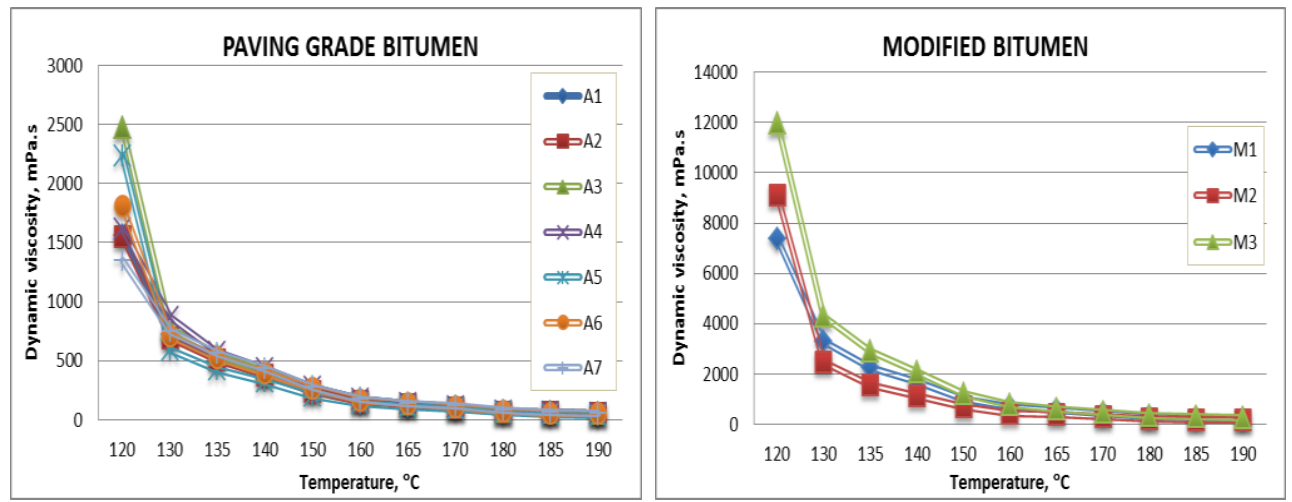

Fig. 4. Dynamic viscosity of tested bitumen binders (paving grade - left, modified - right).

In the following steps, the relationship between viscosity and softening point and penetration for particular bitumen was studied. If the relationship exists, it is important know how greatly the softening point and penetration influence the dynamic viscosity of 
bitumen binders. Relation between viscosity and softening point respectively penetration is expressed by linear function $y=A x+B$ resp. exponential function $y=A . x^{B}$. The investigated dependencies were processed for all temperatures at which the dynamic viscosity was measured (from $120^{\circ} \mathrm{C}$ to $190{ }^{\circ} \mathrm{C}$ ). In all cases, for paving grade bitumen, decreasing dependencies were found. The highest dependence between penetration and viscosity was found at a temperature of $140{ }^{\circ} \mathrm{C}$, between the softening point and the viscosity at temperature $120{ }^{\circ} \mathrm{C}$. For modified bitumen, the situation is slightly different. For dependence between penetration and viscosity, the dependencies were decreasing, but in the case of softening point and viscosity the dependencies were already increasing. The highest dependence between penetration and viscosity was found at a temperature of $165^{\circ} \mathrm{C}$, between the softening point and the viscosity at $165^{\circ} \mathrm{C}$. Specific dependencies are explained below in the text.
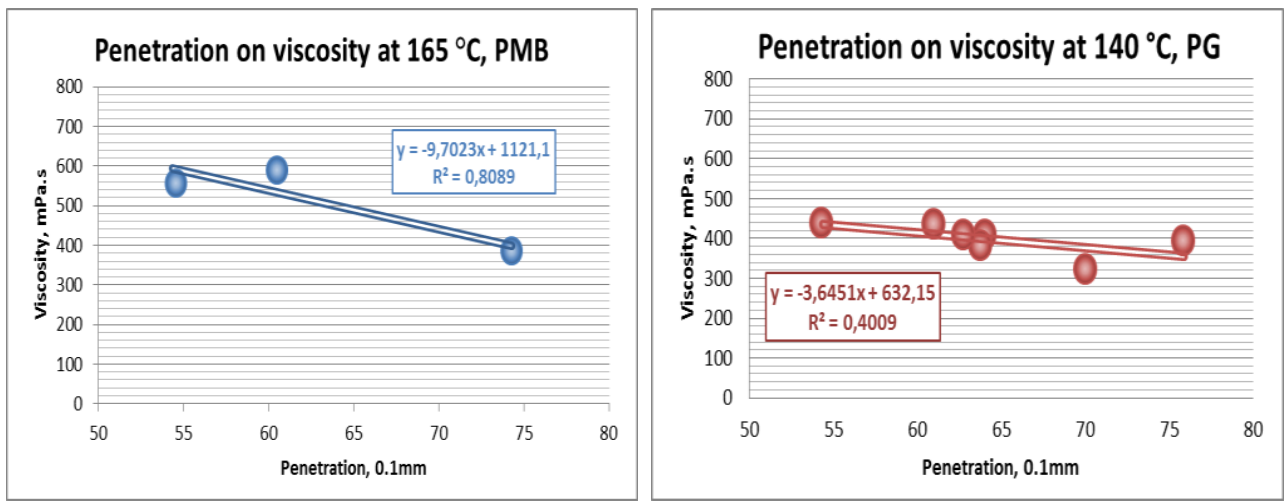

Fig. 5. Dependence of dynamic viscosity on penetration, modified bitumen (left), paving grade bitumen (right).

Regression dependence of viscosity and penetration bitumen in the Figure 5 (linear) shows high values of determination coefficient $\mathrm{R}^{2}$ for polymer modified bitumen and middle values of determination coefficient $R^{2}$ for paving grade bitumen. Values of reliability in relation between viscosity and penetration are in range from 0.8089 (at temperature of viscosity $165^{\circ} \mathrm{C}$ ) for modified bitumen and to value 0.4009 (at temperature $140{ }^{\circ} \mathrm{C}$ ) for paving grade bitumen, what means correlation in range of 0.894 (polymer modified bitumen) to 0.632 (paving grade bitumen). These values of correlation give assumption that between viscosity and penetration some dependence exists. Based of charts, for both types of bitumen binders we can state that, the viscosity decreases with increasing penetration.

In relation between viscosity and softening point occurs different situation. Regression dependence of viscosity and softening point bitumen in the Figure 6 (linear for modified bitumen and exponential for paving grade bitumen) shows average values of determination coefficient $\mathrm{R}^{2}$ for polymer modified bitumen and lower values of determination coefficient $\mathrm{R}^{2}$ for paving grade bitumen. Values of reliability in relation between viscosity and softening point are in range from 0.673 (at temperature of viscosity $165{ }^{\circ} \mathrm{C}$ ) for modified bitumen and to value 0.233 (at temperature $120^{\circ} \mathrm{C}$ ) for paving grade bitumen, what means correlation in range of 0.820 (polymer modified bitumen) to 0.482 (paving grade bitumen). These values of correlation give assumption that between viscosity and softening point some dependence exists. Based of charts, for modified bitumen binders we can state that, the viscosity decreases with increasing softening point, but for paving grade bitumen we can state that, the viscosity decreases with the increasing softening point. 


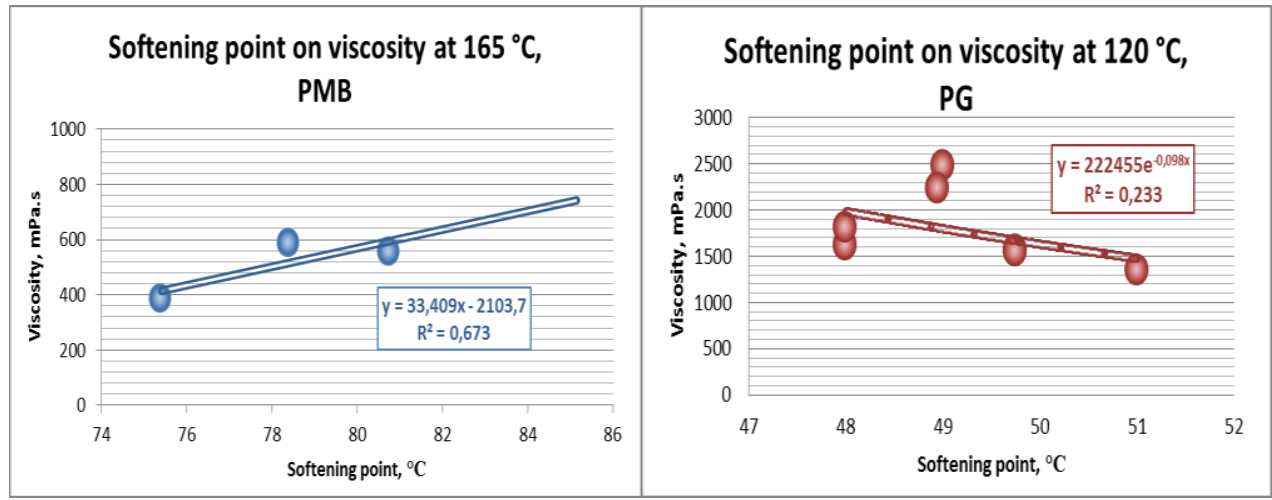

Fig. 6. Dependence of dynamic viscosity on softening point, modified bitumen (left), paving grade bitumen (right).

\section{Conclusion}

The quality of bituminous binders used in the construction and maintenance of road surfaces is currently being assessed by empirical tests based on obtaining one value for specific boundary conditions that were designed around 100 years ago. However, these tests, such as softening point, penetration, and the breaking point appears at present to be insufficient for describe the behavior of bitumen binders. The current state of the asphalt roads has led to new ways and approaches for better describe the properties of binders and mixtures. One of this approach to assessment of bitumen in terms of operational performance is so-called "performance-based approach". One of the tests from this approach is also a test of dynamic viscosity.

Therefore the goal of a study was determine correlation of viscosity and physical properties to explain in order to characterize the basic properties of bitumen binders. From the results we can say that despite the same grading of bitumen, we can see the high variability of the results of dynamic viscosity (more visible for lower temperatures), with higher the temperature, the variability of values of dynamic viscosity is smaller for both type of bitumen. Differences in dynamic viscosity values can be attributed to the fact that each of bitumen was from another manufacturer (both for paving grade bitumen and for modified bitumen - for modified bitumen show differences of dynamic viscosity of already 3 samples of bitumen). The relationship between viscosity and softening point and penetration for particular bitumen was studied. In all cases, for paving grade bitumen, decreasing dependencies were found. The highest dependence between penetration and viscosity was found at a temperature of $140{ }^{\circ} \mathrm{C}$, between the softening point and the viscosity at $120{ }^{\circ} \mathrm{C}$. For modified bitumen, the situation is slightly different. For dependence between penetration and viscosity, the dependencies were decreasing, but in the case of softening point and viscosity the dependencies were already increasing (due to polymer modificator). The highest dependence between penetration and viscosity was found at a temperature of $165^{\circ} \mathrm{C}$, between the softening point and the viscosity at $165^{\circ} \mathrm{C}$. Intermediate dependencies have been discovered between binder penetration and dynamic viscosity at a specific temperature (correlation in range of $0.894 \mathrm{PMB}$ to $0.632 \mathrm{PG}$ ) and softening point and dynamic viscosity at a specific temperature (correlation in range of $0.820 \mathrm{PMB}$ to $0.482 \mathrm{PG}$ ). However, it should be noted that this correlation was only issued for three PMB samples. These results give assumption for further research. 
The authors are grateful for the financial support from the research project VEGA 1/0300/17 Research of performance related and rheological properties of bituminous binders.

\section{References}

1. P. Coufalík, Rheological properties of bitumen binders Thesis, Brno University of technology. (2017)

2. Proceedings of Technical Sheets - CESTI 2014 Available from:

$<$ http://www.cesti.cz/technicke_listy/t12014/Sbornik_TL_CESTI_2014.pdf >

3. Brookfield engineering laboratories, inc. Brookfield DV-II+Pro, Operating Instructions 3 Manual No. M03-165-E0211, USA

4. M. Holý, E. Remišová, Evaluation of bitumen binders properties 9th International Scientific Conference of Civil Engineering and Architecture, ISBN: 978-80-553-31362 (2017)

5. Nur Izzi Md. Yusoff et al., Modelling the linear viscoelastic theological properties of bituminous binders. In: Construction and Building Materials Vol. 25, ISSN 2171-2189 (2003)

6. K. Kováŕík, D. Sitányiová, M. Drusa, Hydraulika a hydrológia (in Slovak), Hydraulics and hydrology University textbook. 1. EDIS - Žilina, ISBN ISBN 80-8070-037-0 (2003)

7. EN 1426. Bitumen and bituminous binders. Determination of needle penetration. (2010)

8. EN 1427. Bitumen and bituminous binders. Determination of the softening point. Ring and Ball method. (2010)

9. EN 13302. Bitumen and bituminous binders. Determination of dynamic viscosity of bituminous binder using a rotating spindle apparatus. (2010) 